\title{
Translation and Authority-Authority in Translation, P. De Leemans and M. Goyens (ed.)
}

\section{Paola Cifarelli}

\section{(2) OpenEdition}

1 Journals

\section{Édition électronique}

URL : http://journals.openedition.org/studifrancesi/10517

DOI : 10.4000/studifrancesi. 10517

ISSN : 2427-5856

Éditeur

Rosenberg \& Sellier

\section{Édition imprimée}

Date de publication : 1 décembre 2017

Pagination : $528-529$

ISSN : 0039-2944

\section{Référence électronique}

Paola Cifarelli, «Translation and Authority-Authority in Translation, P. De Leemans and M. Goyens (ed.)», Studi Francesi [En ligne], 183 (LXI | III) | 2017, mis en ligne le 01 février 2018, consulté le 23 janvier 2021. URL : http://journals.openedition.org/studifrancesi/10517 ; DOI : https://doi.org/10.4000/ studifrancesi. 10517

Ce document a été généré automatiquement le 23 janvier 2021.

\section{(c)}

Studi Francesi è distribuita con Licenza Creative Commons Attribuzione - Non commerciale - Non opere derivate 4.0 Internazionale. 


\title{
Translation and Authority-Authority in Translation, P. De Leemans and M. Goyens (ed.)
}

\author{
Paola Cifarelli
}

\section{RÉFÉRENCE}

Translation and Authority-Authority in Translation, edited by Pieter DE LEEMANS and Michèle GOYENS, Turnhout, Brepols, 2016, «The Medieval Translator-Traduire au Moyen Âge» 16.

1 Les communications réunies dans ce nouveau volume de la collection «The Medieval Translator» sont consacrées à la question complexe de la relation entre la pratique de la traduction et l'autorité; comme l'expliquent les éditeurs dans l'Introduction, cela amène à réfléchir sur la portée de l'influence exercée par le texte-source et son auteur sur le texte-cible et sur les choix du traducteur pour évaluer, entre autres, les moyens dont celui-ci dispose pour exercer son emprise sur le texte d'arrivée et les conditions qui font de certaines traductions de nouveaux textes faisant autorité. La fourchette chronologique étendue (du début du $\mathrm{VI}^{\mathrm{e}}$ jusqu'à la fin du Xvi $\mathrm{I}^{\mathrm{e}}$ siècle) et les domaines géolinguistiques variés ( $\mathrm{du}$ grec et latin à l'anglais, italien, allemand, néerlandais et français) dans lesquels les articles s'insèrent permettent un regard d'ensemble et une perspective ample sur ce phénomène transversal aux différentes cultures. Nous rendons compte ici des communications intéressant le Moyen Âge tardif dans le domaine gallo-roman.

2 Joëlle Ducos (Que traduire en français? Traductions uniques et traductions multiples, pp. 39-52) exploite les données disponibles dans le répertoire Transmédie pour montrer, d'une part, l'importance du nombre des mises en français réalisées au cours du Moyen Âge et du rôle que certaines de celles-ci ont joué sur la culture médiévale, et d'autre part la place occupée par les textes religieux et philosophiques pour la construction d'une culture laïque dominée par la volonté d'édification. Le $\mathrm{xv}^{\mathrm{e}}$ siècle, avec les 
nombreuses retraductions de textes classiques et l'influence exercée par les premiers Humanistes, occupe une place à part pour la naissance du concept d'autorité; cependant, la liste des textes traduits qui, pour leur diffusion et pour le nombre des mises en français, étaient considérés fondateurs dans les différents domaines de la culture permet de mesurer la distance qui sépare notre conception moderne de celle élaborée au Moyen Âge. Les nombreuses pistes de recherche signalées par l'A. montrent la fécondité de ce champ d'études selon plusieurs perspectives, de la littérature et la langue jusqu'à la sociologie et l'histoire culturelle.

3 La perméabilité des frontières entre traduction et écriture à l'époque du premier Humanisme est au cœur de l'article de Graziella PASTORE (Langue de l'aucteur' et langue du 'translateur'? Réflexions sur la langue de Nicolas de Gonesse, pp. 83-96), qui analyse la partie de la traduction des Facta et dicta memorabilia de Valère Maxime due à la plume de Nicolas de Gonesse pour montrer qu'une distinction peut être établie entre deux modes d'écriture de ce clerc à l'intérieur du même texte: la fidélité à la structure syntaxique et lexicale de sa source, qui amène souvent à un texte-cible peu lisible et nécessitant un effort d'interprétation, s'oppose à des passages plus fluides, moins remplis de latinismes et plus spontanés là où le traducteur, dans ses commentaires, traduit d'autres sources, comme Lucain et Suétone. Une distance nette sépare donc la pratique de traduction des textes-sources utilisés pour le commentaire, dont la fonction est d'assurer la compréhension du modèle, de celles utilisées pour les Facta et dicta, destinés aussi à forger un lexique de spécialité dans le domaine du droit, de la politique et de la civilisation romaine.

4 Ce sont encore les questions liées au développement, au Xv siècle, d'une terminologie spécifique et savante en langue vernaculaire qui priment dans l'étude des traductions de textes médicaux menée par Ildiko VAN TRICHT (L'autorité et le développement d'une terminologie médicale aux XIV et $X V^{e}$ siècles, pp. 155-170). L'A. étudie les traductions de trois ouvrages de chirurgie (la Chirurgia d'Henri de Mandeville, la Chirurgia Magna de Guy de Chauliac et la Chirurgia de Guillaume de Salicet), qui jouissent d'une autorité particulière dans la culture médiévale française tant pour la langue dans laquelle ils ont été rédigés que pour l'impact qu'ils ont eu sur le développement de cette branche de la science. La terminologie utilisée par les traducteurs, qui va de la reprise de termes latins sans faire de traduction jusqu'à la création de termes indépendamment de l'influence du latin, témoigne d'une grande disparité liée aux différences dans les procédés utilisés pour la traduction, à leur tour miroir des attitudes diverses envers les textes de départ.

5 L'autorité d'un des textes vernaculaires fondateurs de la culture littéraire italienne et les stratégies adoptées pour l'acclimater en France permettent à Stefania VIGNALI (À propos de la première traduction de l'“Enfer" de Dante: un modèle poétique?, pp. 229-240) de formuler quelques hypothèses à propos du milieu culturel dans lequel la première mise en français de l'Enfer de Dante aurait été réalisée, au tournant du xvI ${ }^{e}$ siècle. Après avoir situé cette traduction dans le contexte des transpositions d'ouvrages italiens réalisées à la même époque, l'A. prend en compte des questions de mise en page dans le manuscrit unique qui nous a transmis le texte, ainsi que la technique de versification utilisée pour le texte français; le choix de la rime tierce, l'utilisation de l'alexandrin et la valeur symbolique attribuée à ce mètre par le traducteur, ainsi que le traitement de la coupe féminine à la césure permettent de formuler l'hypothèse que cette traduction, conçue pour montrer la 'concorde' entre toscan et français et «créer une relation symbolique» 
entre texte-source et texte-cible (p. 239), aurait pu être élaborée dans un contexte bourguignon, peut-être proche de Jean Lemaire de Belges. Des enquêtes plus approfondies pourront vérifier si cette piste de recherche se révèlera fructueuse. 